\title{
ICT TOOLS TO SUPPORT CLIMATE CHANGE ADAPTATION IN THE WATER SERVICES SECTOR: CASE STUDY MAURITIUS
}

\author{
Reshma Sunkur, Olivier St. Flour, Chandradeo Bokhoree \\ School of Sustainable Development and Tourism \\ University of Technology, Mauritius
}

\begin{abstract}
Technological innovation over the past years has reshaped the water sector, allowing conservation and optimized use of this valuable commodity as well as protect nations against water related disasters. Water adaptation has now become primordial in the face of climate change since it is one of the most important resources on which human life depends in addition to economic activities and societal well-being. Yet, smart water application is not simply adhering to technological paraphernalia and trend, but to contextualize the need and investment for long term gains and sustainability. This is especially important for the SIDS such as Mauritius which are specially at risk to water stresses in the future both due to their geographical locations and availability of resources. The aim of this study was to review the ICT tools that are in use in the water services sector and identify their strengths and weaknesses in order to select the most appropriate one for a coastal nation like Mauritius. 60 papers and 9 tools were selected and an evaluation matrix was created to assess their pros and cons in order to identity the most relevant one in the local context. Thus, based on the criteria chosen, sensors and GIS were deemed as the most suitable ICT tools that Mauritius can apply to engage in water smartness.
\end{abstract}

Keywords - Water adaptation, ICT tools, Mauritius, climate change

\section{INTRODUCTION}

The FAO reports that ICT tools are now critical facilitators in the management of water as a natural resource and to achieve the Sustainable Development Goals and the Paris Agreement on climate change [1]. Over the past decades, many regions of the world have witnessed a growing demand in water, more risks of pollution to water supplies, more severe water stress episodes and more water related disasters. At the same time, the irreplaceable and leading role that water plays in sustainable development has become increasingly recognized [2]. For instance, water is specifically mentioned in SDG 6: Clean water and sanitation which is linked to other SDGs like climate change (SDG 13) and sustainable cities and communities (SDG 11). According to [3], at least one in four people will live in a country affected by chronic or recurring shortages of water by 2050 . Simultaneously, the demand for water at personal, household and commercial levels has increased thus further pressurizing the sector which is already subject to poor management, pollution and climate change [1].

To develop smart water techniques in water systems as well as its implementations, technology is required. Smart water systems improve water networks that have been degraded, irregular supplies and low levels of customer satisfaction [2]. At its core, ICT helps in the way the water sector is designed, operated and optimized with long term projects now becoming reliant on modeling and smart metering helping to optimize water supply, demand and forecast [4]. This millennial sector with slow technological progress has already greatly benefitted from the ICT advances. These tools are in the form of databases, web applications, sensors, radio broadcasts, mobile phones, social media, GIS, commercial and off-the-shelf software, custom built and free open source software. Moreover, ICT tools are one of the best ways to facilitate capacity building and institutional strengthening of providing agencies and stakeholders engaged in different cycles of disaster management as well as aid in weather forecasting, climate monitoring and hazard mapping in this climate change period [5].

Water resources and their management play a major role in all aspects of society and the economy such as health, domestic water supply, energy, sanitation, food production and security and the functioning of ecosystems [3]. Climate change adds an urgency for action in the water sector as well as disaster risk management. Innovative solutions and integrated solutions are required to adapt and to decrease the inadvertent effects on the environment and human health. It is already obvious that climate change is having an impact on the water sector at all scales and thus it is vital to strengthen the ability to adapt to these changes in such a way that also mitigate hazards and related risks to humans and the environment through a combination of technological and technical expertise [6]. Thus, the purpose of this paper was to 


\section{International Journal of Engineering Applied Sciences and Technology, 2021 \\ Vol. 6, Issue 4, ISSN No. 2455-2143, Pages 212-219 \\ Published Online August 2021 in IJEAST (http://www.ijeast.com)}

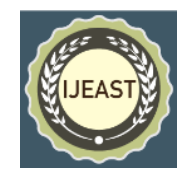

review the ICT tools that are in use in the water services sector and identify their strengths and weaknesses in order to select the most appropriate one for an island nation like Mauritius.

\section{MATERIALS AND METHODS}

To obtain an overview of the ICT tools in use in the water services sector, a comprehensive search was conducted on Google Scholar using keywords including 'ICT Tools' AND 'water', 'smart water', 'water adaptation', 'water management AND ICT Tools', sorted by relevance. Google Scholar was deemed appropriate for this study as it is an accessible web engine that is free and indexes scholarly publications across various disciplines and format [7]. An advanced search with the above-mentioned keywords 'in the title of the article' only resulted in 0 results, so a simple search 'with all of the words' in the articles was conducted to retrieve the relevant articles. A screening process was then conducted to grab papers relevant to the purpose of this study as the topic is very broad. The analysis was carried out by examining specific reports related to water management such as the UN Water Reports, technological sites on smart water management like ITU and various online publications based on water management and ICT tools from journals like Water, Climate Change Adaptation, Water Environment and Water Resources Management and ICT Journals.

60 papers were finally selected and 20 ICT tools were identified as relevant to the water services sector. A final screening resulted in the selection of 9 tools as appropriate for SIDS like Mauritius. Following [8], a three-step approach was used to identify and clarify the differences of the existing ICT tools. In step 1 of the assessment, criteria were developed to assess the properties of the different tools. In step 2, the tools' strengths and weaknesses were evaluated based on the developed criteria. In step 3, the results of the analysis were summarized and structured as a matrix to distinguish their relevancy context-wise.

5 common criteria were formulated for a broad application of these tools. Thus, to be able to find a useful tool for Mauritius, these 5 criteria need to be fulfilled.

\section{Functionality}

A smart water management tool must serve its purpose well. Functionality refers to the functions and/or capabilities of the tool in relation to computer software or hardware or an electronic device. Some tools may be more user friendly but may not output the required results. In this way, some tools may not be applicable to certain regions or the assessment may not be comparable.

\section{Ease of use}

The ease of use of any smart water management tool is very important. The tool must be easy to use and its complexity must be on a reasonable level to be accessible to different types of users. Detailed, highly complexed tool may present results very accurately, but the time required to understand the underlying processes can be excessive. For instance, the non-technical user must be able to learn the technicalities within two/three months instead of two/three years. Technical expertise in specific fields required to run the model may also be unavailable. Generally, a good smart water tool must be fairly ease to comprehend; additional technical expertise to run the model must be within the understanding of the modeler instead of outside his/her capabilities.

\section{Applicability}

Tools must be applicable on the SIDS level. Tools developed for large countries may not be applicable for small islands as the parameters and settings are different. While some tools may be highly effective for their purposes, if they cannot be downscaled to the small sizes of the SIDS, they are of no use.

\section{Cost effectiveness}

The cost of smart water management tools plays a critical role in their acquisition in SIDS. Cost effectiveness refer to the good value of a tool where the benefits and usage are worth what is being invested in. Some tools present highly reliable, real-time, and accurate data but are very expensive. Similarly, some high precision tools may cover large areas but are not cost effective for small islands. Ideally, a smart water tool for SIDS like Mauritius must be cost effective such that the funds being invested will reap benefits.

\section{Availability of local support}

One critical element when it comes to smart water management in SIDS is the availability of local support. In general, small islands are lagging behind in terms of technological advancement due to a lack of finance and technical expertise in particular fields. While some tools may be ideal context wise, local support in case of technical issues must also be available. If support for any specific tool is outside the reach of the island, it may not be useful.

\section{RESULTS AND DISCUSSION}

\subsection{Review of ICT tools in the water services sector}

\subsection{Smart water applications}

Smart water management systems include a vast range of hardware and software such as sensors, actuators, meters, data processing and visualization tools, web and mobile applications that connect people with water systems. Typically, smart water management is based on the integration of hardware systems and the adoption of measures to control, monitor and regulate water quality, its use and maintain the quality of equipment [10]. Smart water management ensures that: 


\section{International Journal of Engineering Applied Sciences and Technology, 2021 \\ Vol. 6, Issue 4, ISSN No. 2455-2143, Pages 212-219 \\ Published Online August 2021 in IJEAST (http://www.ijeast.com)}

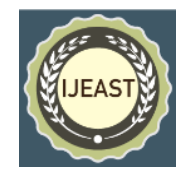

- There is less wastage of water in fields such as agriculture, manufacturing and power production and may include the adoption of practices such as precision farming, smart irrigation and real time water metering.

Water quality is improved by preventing contamination with pollutants through the use of sensors for real time monitoring and control.

The efficiency of water systems is enhanced like water collectors, distribution pipes, treatment plants and wastewater recycling centers by using IoT and data solutions to monitor water pressure, flow and temperature for maintenance and avoid breakage and downtime.

Leakage control is well established through devices equipped with moisture and leak sensors and thus save on budgets and prevent water loss.

Consumption monitoring is practiced at all levels, from household level to a global level.

\subsection{ICT tools in the water services sector}

[11] gives a detailed account of the current technology that is currently applied in smart water management ranging from digital output instruments like sensors and smart meters such as rain gauges and acoustic devices to measure leakages to Supervisory Control and Data Acquisition Systems (SCADA) to operate devices remotely. Similarly, [6] for the UN Environment list 102 water adaptation technologies to climate change and disaster management including downscaling of climate model projections, disaster risk assessment using LiDAR, decision scaling systems, basin level modeling and seasonal forecasting, water metering and multipurpose dams amongst others. Nevertheless, a detailed review of specific individual tools that are used in the broad water and waterrelated sector was beyond the scope of this study. Subsequently, the most relevant ICT tools for water management were considered as follows: satellites, radars, LiDAR, Unmanned Aerial Vehicles, sensors, buried asset identification and electronic tagging, modeling software, smart pipes, smart metering and smart grids.

\subsubsection{Satellites}

Artificial satellites have been operational since the mid20th century. Today, there are hundreds of satellites orbiting the Earth capturing a variety of data on water parameters via sensors [11]. Satellite estimates are widely used especially in oceanography. The use of satellite data to monitor water quality focuses mainly on developing algorithms with band combinations within the visible and infrared portion of the electromagnetic spectrum [12]. [13] declare that remote sensing using satellite is an effective toll for soil moisture assessment, groundwater management, water and water quality monitoring, flood mapping and water demand modeling. In line with this, [11] emphasize that the large use of satellite data is due to its near-continuous large spatial coverage, its ability to cover remote and inaccessible areas as well as its relatively long record of archived imagery. Nevertheless, as pointed out by [14], satellite estimates also have significant disadvantages. First, it is difficult to distinguish among the various water components. Second, the sampling is limited to the surface and depends on the clarity of the water and third, the spatial and temporal resolution can be inadequate and uncontrollable. [15] further contend that while spatial resolutions of satellite images are evolving, these are in proportion to higher costs.

\subsubsection{Radars}

Radars (radio Detection and Ranging) are devices that locate weather components, calculate their motion, estimate their type and make forecast on their location and intensity [16]. Doppler radars are the most common weather radars that detect the motion of rain droplets as well as the intensity of precipitation both of which can be used to determine storm structures and their potential to extreme weather conditions such as floods. Nowadays, digital radar systems have the ability to track storms thus providing user with valuable information on storm movement. Raw data is first preprogrammed into the radar system and used to identify storms based on the information received by the radar pulse. Once a storm is spotted, its direction, speed, spatial coverage and estimated time of arrival can be inserted into the memory of the radar system for later use. [17] state that radars are accurate tools with high imaging capacity through any type of weather condition. They also use low transmitting power and are generally small in size with simple circuits. Nevertheless, as [18] points out, several targets can lead to confusion in the system and complex, expensive circuitry must be used to obtain range discrimination. [17] further declare that there can be poor motion detection due to the short time required to collect coherent data from moving targets.

\subsubsection{LiDAR}

LiDAR (Light Detection and Ranging) is also a remote sensing method which makes use of light in the form of pulsed laser in order to measure variable distances to the Earth. Combined with other recorded data, these light pulses can generate high precision, 3-D information on the shape and characteristics of the Earth such as water bodies. LiDAR principally consists of a specialized GPS receiver, a laser and a scanner and are basically used to capture bathymetric and topographic information. Commercial sensors have increased in the last two decades as well as the number of firms that provide LiDAR data services [15]. [19] contend that using LiDAR, data can be obtained quickly and accurately and they also cover regions which can be difficult to access. Yet, [15] point out that they are quite expensive to operate, ineffective during heavy rain and low cloud cover, can be degraded at high sun angles and precise alignment must be maintained for good measurement. 


\section{International Journal of Engineering Applied Sciences and Technology, 2021 \\ Vol. 6, Issue 4, ISSN No. 2455-2143, Pages 212-219 \\ Published Online August 2021 in IJEAST (http://www.ijeast.com)}

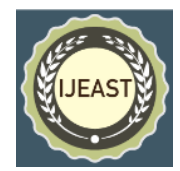

\subsubsection{Unmanned Aerial Vehicles}

Unmanned Aerial Vehicles (UAV) or drones are increasingly being used by researchers for watershed monitoring and mapping. [20] explain that UAVs can capture Structure from Motion (SfM) 3-D point clouds on their digital images just like LiDAR imagery. For example, Terra Drone India used drones to undertake an aerial survey of $4200 \mathrm{~km} 2$ of agricultural land for the Water Resources Department of the Maharashtra Government to manage water more efficiently [21]. [14] state that the use of drones in natural resource [22, 23], forests [24], vegetation and biomass [25] monitoring, management and evaluation has increased significantly in the past 10 years. Generally, UAVs present low costs compared to satellites for high resolution imagery as well as lower operational costs, can hover over an area for as long as needed, provide high resolution images, can be used in any season and time of the day and the images are immediately accessible [14]. However, ground control with some training is required to manipulate drones, maneuverability must be practiced, there can be data overload and hacking and drone flying must be legally approved [14].

\subsubsection{Sensors}

For decades, networks of in-situ sensors have been set in place in the meteorological stations to capture real time data and help in weather forecasting. As the technological field advances, unattended sensors and wireless telecommunication technologies are being used for new purposes such as climate monitoring for long term climate prediction. Today, it is even possible to provide quality controlled network wide information to users via the Internet in real time or as data assimilated in models within hours [26]. Various sensors are used in the water services sector ranging from motion detectors installed in latrines to monitor usage or adoption flowmeters to conventional water quality sensors. Basically, sensors pick up stimuli like motion into electrical signals; these are then passed through an interface that converts them into a binary code and passes this on to a computer to be processed. The most common types of sensors in the water sector are water quality, microbial and chemicals sensors. [26] declare that evolution in the sensing technology has led to today's smart and fast sensors that can capture real time data at high speed on almost lossless transmission. Broadly speaking, sensors accelerate processes and make them quite accurate, collect data in real time, monitor processes accurately, increase productivity and reduce total cost of ownership with lower energy wastage. But [14] indicate that the environment where the sensor is placed can be often distant and power-constrained; there is a high degree of variability in the environment such as the type of material, age, servicing, quality and functionality. Thus, all these conditions must be considered while engaging in electronic sensor based solutions.

\subsubsection{Geographical Information Systems (GIS)}

[27] propound that the formidable explosion in computer technology has made it possible and easier to now capture and develop computer applications that address specific problems, manipulate and analyze large scale information related to the water sector. Nowadays, many organizations use GIS to address water related issues ranging from non-point source pollution to monitoring of flow and pollutants in storm sewer networks. GIS was developed in Canada in the 1960s and over the years it has been polished into the now commonly used mature industry. The technology is actually a collection of computer software and data that is used for displaying, analyzing, managing and visualizing geographical information. It is strongly linked to geography, cartography and computer science and is immensely used for geographical information management. GIS helps in decision making by visualizing scenarios and regions, has low cost and even free versions and provides easy record keeping. As concurred by [27], GIS software has drastically changed the way engineers and scientists model water resources from surface water hydrologic modeling, water supply and sewer systems modeling, non-point source pollution for agricultural and urban regions, groundwater modeling, floodplain management, Environmental Impact Assessment studies, landscaping, erosion and sedimentation leading to better estimates and more effective management practices. However, in order to use GIS, some technical training is required and high resolution maps must be available for accurate results.

\subsubsection{Smart pipes}

With the great advances in technology over the past decade, there has been major developments within sensor systems and engineering which have made smart pipes a reality. Many cities that are making use of smart pipes are actually saving much on their investments such as Tokyo which reports savings of \$USD 170 million per annum just in detecting water loss in leakages and acting on the spot [28]. Over the years, several methods and techniques have been developed to monitor and assess the conditions of water pipes, especially in leak detection. These include the SaharaTM equipment using acoustic methods, remote eddy current techniques and intelligent pigs using magnetic flux leakage [28]. Recently, innovative alternatives for detecting leaks in water pipes such as the Smart BallTM, have come on the market; it consists of a 'ball' with acoustic sensors capable of capturing data that is inserted into water and waste water pipes. In the same manner, Ground Penetrating Radar (GPR) is being used to detect pipelines as well as leaks and defects. [28] state that strategic placement of these sensors which are themselves found on boards that form part of a wider network that monitor and respond to water loss in pipes in an urban area, can ensure city-wide coverage of leak detection. Data collected by the sensors can be sent to the service providers to analyze water loss problems and take the required actions. Also, data can be sent via the Internet to local communities, industries, customers and the public at large to encourage 


\section{International Journal of Engineering Applied Sciences and Technology, 2021 \\ Vol. 6, Issue 4, ISSN No. 2455-2143, Pages 212-219 \\ Published Online August 2021 in IJEAST (http://www.ijeast.com)}

water saving practices and thus better manage water. Nevertheless, as pointed out by [28], these techniques rely on personnel going on site to do the investigation of pipes and are thus labor intensive and time consuming. Furthermore, though there are sensors that can be placed at specific points like valve location to do spot checks on water quality, sensors for detecting pipe deterioration or leak are not commonly used for water pipes as they are expensive and inaccessible underground.

\subsubsection{Smart metering}

Smart metering is increasingly being used by water utilities to conduct frequent meter reads of customers' water usage throughout the day with real time information on water consumption and to detect water losses [29]. Through the secure national communication network, Data Communications Company (DCC) smart meters monitor water usage automatically and wirelessly and send the data to the provider. Many cities such as San Francisco are actually using the one-way automated meter readers called the Automatic Meter Readers (AMR) that send data on water usage to the service provider. Advanced Metering Infrastructure (AMI) is a two-way network in which water consumption data is sent to the utility as well as the consumer is also becoming common. By so doing, smart meters can be read remotely and the consumer can gather information on water consumption. Smart meters offer several benefits such as leak detection, energy reduction, enhanced water consumption awareness, performance indicators, and demand forecasting. Additionally, smart apps can be developed for a neighborhood to allow water consumption comparison [29]. However, there have been complaints about health issues regarding smart meters since they emit radiation 24 hours a day [30] and relating to the ease of use of the applications.

\subsubsection{Smart grids}

Smart grids are now being promoted as a means to increase energy efficiency and tackle issues such as global warming, sustainability, decrease reliability on electric power generation and national security. The term smart grid refers to a collection of technologies such as smart meters and paraphernalia, monitoring systems, radio communications technology, electromagnetic signature analysis, time of use and real time pricing tools, dynamic line evaluation, advanced switches and cables and digital protective relays as well as databases to store the information and provide it to provider staff and consumers. Smart grid provides the technology to create a supply-demand relationship between service providers and customers, thus causing the clients to be aware of their water usage. Since both water and wastewater utilities use a lot of energy to operate, smart grids can decrease the dependency on energy consumption on many fronts, decrease operational costs, streamline operations and maintenance as well as improve data management. Yet as [31] points out, this type of technology is quite expensive with load factors increasing in relation to the efficiency of the system.

\subsection{Smart water application in Mauritius}

The concept of smart cities in Mauritius is already ongoing with projects such as the Mon Tresor Smart City, Cap Tamarin Smart City, Uniciti, Moka City, and Jin Fei Smart City already approved by the Economic Development Board of Mauritius. From proper waste water treatment to water resource conservation, these projects are aimed at developing sustainable solutions and ensuring minimum wastage of resources to the communities while delivering a happier lifestyle. Also, the use of sensors in water conservation in Mauritius is well established both in the private sector and public places. [32] highlight how the tourism sector makes use of desalination technology, rainwater harvesting, water tank construction, waste water management practices to conserve and exploit water resources. In fact, promoters are even encouraged to use water saving devices be it for consumption, recreation or landscaping purposes [33].

In its Third National Contribution to the UNFCCC, the Government of Mauritius lists a series of measures to save water and also become water resilient in the future in the form of modernization of the supply and distribution of water. As it is, one of the most problematic issues regarding the water sector of Mauritius is the leakage in potable water storage and distribution system. Unaccounted For Water (UFW) is relatively high causing Mauritius to be 'water stress' and unable to supply water on a 24 hour basis. In its 2018-2019 budget, the [34] made provision for a better water supply infrastructure over the island in order to improve water supply. It included the replacement of water pipes, the construction of reservoirs, the replacement of some 75,000 water meters and the construction of a water treatment plant at Bagatelle. Yet, there is no wide application of technological tools in the water sector of Mauritius as reflected by the Central Water Authority's services and projects webpage [35]. Recently, as a consequence of the COVID-19 confinement, the CWA has initiated the Scan and Pay to help the citizens pay their bills online. Similarly, the [36] is redesigning the agriculture sector with a smart methodology based on technological innovation. This includes the involvement of the agricultural community from the small farmers to the corporates for the system to be effective. In fact, as far as 2006, [37] suggested the use of treated waste water to irrigate crops during the dry seasons and artificial recharging of aquifers to decrease wastage of water but due to financial constraints that such projects represent, alternatives were chosen. In the same vein, hydropower in Mauritius has been ongoing since 1899 in order to produce electricity. Over the years there has been many technical changes in hydro-electricity production to optimize the use of the resource while taking into consideration natural hazard management such as flooding and climate change [38]. While it is widely acknowledged that hydropower in Mauritius 


\section{International Journal of Engineering Applied Sciences and Technology, 2021 \\ Vol. 6, Issue 4, ISSN No. 2455-2143, Pages 212-219 \\ Published Online August 2021 in IJEAST (http://www.ijeast.com)}

is fully tapped, [38] suggests that technical innovation in the sector coupled to better storage facilities could create synergies towards dependence on a renewable energy development.

\subsection{Suitable tool/s for Mauritius}

The above mentioned highlighted properties of the selected ICT tools are presented structurally in Figure 1. Each tool was evaluated based on its fulfilment of the derived criteria: functionality, ease of use, applicability, cost effectiveness and availability of local support for SIDS like Mauritius.

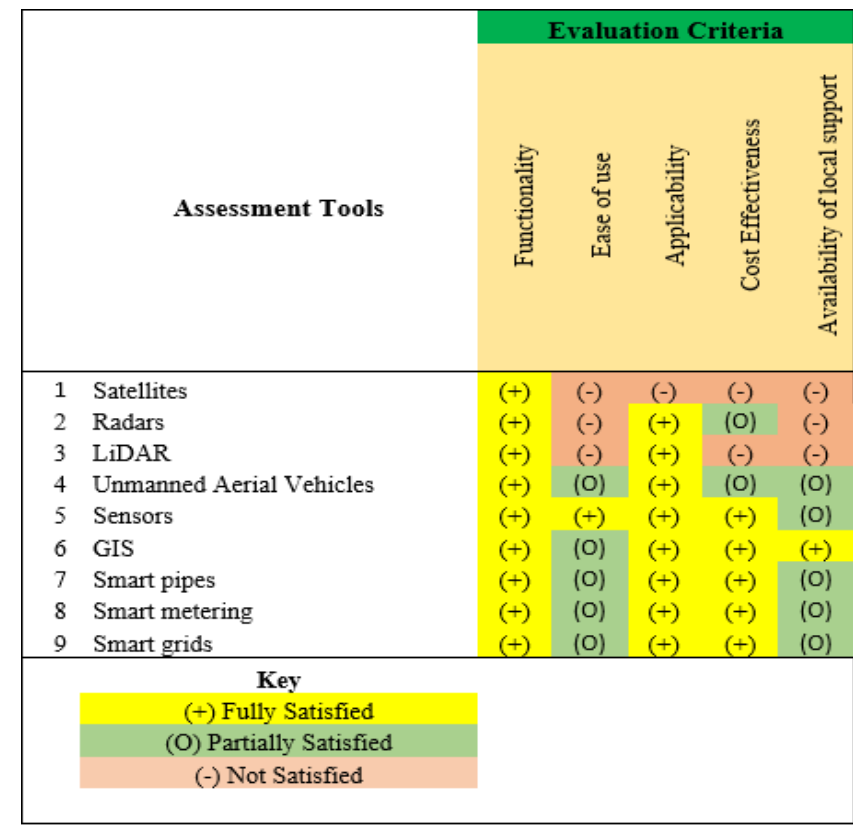

Figure 1: Evaluation matrix of tools

The ICT tools identified as most relevant to the water services sector for small islands including Mauritius are evaluated in the matrix in Figure 1. A single proper tool that fulfills all the criteria could not be identified. Yet, from the figure above, it can be seen that the most relevant tools to SIDS such as Mauritius are sensors and GIS based on the criteria used. Basically, all the tools differ in terms of their functionality, ease of use, applicability, cost effectiveness and availability of local support. For instance, satellites are excellent tools for water monitoring be it on land or in clouds, yet small islands such as Mauritius do not have the technical expertise nor the funds to invest in such instruments. What's more, the size of islands is too small for such gadgets to be used. Similarly, in many cases, there can be a lack of data or no monitoring of the data that is required to feed into the tools for effective results. GIS is deemed as quite an effective method for use in the water services sector as it fulfills most of the criteria. Its functionality, applicability is good, it is cost effective and local support is available. Yet, it requires some technical expertise before handling which can be resolved by training from experts. Similarly, sensors have good functionality, applicability, ease of use and cost effectiveness. However, the specific types of sensors to be used in the water services sector may require support that may not be available on SIDS due to the quality and type of sensor material. For example, SaharaTM uses sophisticated balls with acoustic sensors to monitor water levels in pipes [28] but such kind of expertise is not available in SIDS.

\section{CONCLUSION}

In this study, 60 papers on ICT tools that support adaptation in the water services sector were selected and 9 tools were deemed relevant for use in the SIDS context. They were evaluateV. d using 5 criteria namely functionality, ease of use, applicability, cost effectiveness and availability of local support in order to select the most appropriate one in the local context. GIS and sensors were identified as the most suitable tools based on the above mentioned criteria. With the intensification of the effects of climate change, population growth, urbanization, the disparity between water demand and supply also rises resulting in water security problems and conflicts. Thus, Mauritius has to start on a smartness concept that can be applied to the nation and resources available while providing sustainability and an uplift in the standard of living of the nation. Given the expense associated with technological innovation in the water sector, to date, many developed countries are still piloting small scale projects to test costeffectiveness in the long run. Consequently, even small island nations like Mauritius have to test certain technological tools and ensure profitability over the years.

\section{REFERENCES}

1. FAO. (2017). ICTs and management of water resources in agriculture. Retrieved July 08, 2020, from http://www.fao.org/e-agriculture/blog/icts-and-managementwater-resources-agriculture

2. Ramos, H.M., McNabola, A., López-Jiménez, P.A. and Pérez-Sánchez, M. (2020). Smart water management towards future water sustainable networks. Water, vol. 12, no. 1 , (pp. 58).

3. UN World Water Development Report. (2020). Water and climate change. [online] Retrieved May 09, 2020, from https://www.unwater.org/publication_categories/worldwater-development-report/

4. Grilo, J. (2016). The impact of ICT in the water sector. IWA. Retrieved February 02, 2020, from https://iwanetwork.org/the-impact-of-ict-in-the-water-sector/

5. Zaman, M.A. and Biswas, A.A.A. (2014). Application of ICT tools for climate change and disaster management in Bangladesh. Proceedings of AFITA.

6. Bertule, M., Appelquist, L.R., Spensley, J., Trærup, S.L.M. and Naswa, P. (2018). Climate change adaptation 


\section{International Journal of Engineering Applied Sciences and Technology, 2021 \\ Vol. 6, Issue 4, ISSN No. 2455-2143, Pages 212-219 \\ Published Online August 2021 in IJEAST (http://www.ijeast.com)}

technologies for water: A practitioner's guide to adaptation technologies for increased water sector resilience. Retrieved March 25, 2020, from https://backend.orbit.dtu.dk/ws/portalfiles/portal/145967791/C C_Adaptation_technologies_for_water_red.pdf

7. Jeyapragash., B., Muthuraj, A., and Rajkumar, T. (2016). Research Publications in Open Access with Special Reference to Directory of Open Access Journal an Analysis. International Refereed Journal. Journal of Current Trends in Libraries and Information Science, vol. 3, (pp. 4-9).

8. Chen, D., Schudeleit, T., Posselt, G. and Thiede, S. (2013). A state-of-the-art review and evaluation of tools for factory sustainability assessment. Procedia Cirp, vol. 9, (pp.85-90).

9. Digiteum. (2019). Smart water management technology and IoT. Retrieved March, 02, 2020, from https://www.digiteum.com/smart-water-management-iot\#1

10. Jung, H.K. (2019). What is smart water management? Retrieved March 15, 2020, from https://development.asia/explainer/what-smart-watermanagement

11. Hellweger, F.L., Schlosser, P., Lall, U. and Weissel, J.K. (2004). Use of satellite imagery for water quality studies in New York Harbor. Estuarine. Coastal and Shelf Science, vol. 61, no. 3, (pp.437-448).

12. Yigit Avdan, Z., Kaplan, G., Goncu, S. and Avdan, U. (2019). Monitoring the Water Quality of Small Water Bodies Using High-Resolution Remote Sensing Data. ISPRS International Journal of Geo-Information, vol. 8, no. 12, (pp.553).

13. Su, Z., Yacob, A., Wen, J., Roerink, G., He, Y., Gao, B., Boogaard, H. and van Diepen, C. (2003). Assessing relative soil moisture with remote sensing data: theory, experimental validation, and application to drought monitoring over the North China Plain. Physics and Chemistry of the Earth, Parts A/B/C, vol. 28, no. 1-3, (pp.89-101).

14. Andres, L., Boateng, K., Borja-Vega, C. and Thomas, E. (2018). A review of in-situ and remote sensing technologies to monitor water and sanitation interventions. Water, vol. 10, no. 6 , (pp.756).

15. Bhardwaj, A., Sam, L., Bhardwaj, A. and MartínTorres, F.J. (2016). LiDAR remote sensing of the cryosphere: Present applications and future prospects. Remote Sensing of Environment, vol. 177, (pp.125-143).

16. Ulaby, F., Dobson, M.C. and Álvarez-Pérez, J.L. (2019). Handbook of radar scattering statistics for terrain. Artech House.

17. Wang, X., Li, J., Yang, Y., Lu, C., Kwan, C. and Ayhan, B. (2011). Comparison of three radar systems for through-the-wall sensing. Radar Sensor Technology XV, International Society for Optics and Photonics, vol. 8021, (pp. $80210 \mathrm{H})$.

18. Arora, A. (2014). Pulse Doppler Radar. Retrieved March 26, 2020, from https://www.slideshare.net/akhilesharora/pulse-doppler-radar

19. Crouch, S. (2018). Advantages of 3D imaging coherent lidar for autonomous driving applications. Proceedings of the 19th Coherent Laser Radar Conference, Okinawa, Japan, (pp.18-21).

20. Harwin, S. and Lucieer, A. (2012). Assessing the accuracy of georeferenced point clouds produced via multiview stereopsis from unmanned aerial vehicle (UAV) imagery. Remote Sensing, vol. 4, no. 6, (pp.1573-1599).

21. Surveyor News. (2019). Maharashtra Government is Using Drones For Efficient Water Management. Retrieved March 21, 2020, from https://www.africasurveyorsonline.com/2019/05/12/maharasht ra-government-is-using-drones-for-efficient-watermanagement/

22. Horcher, A. and Visser, R.J. (2004). Unmanned aerial vehicles: applications for natural resource management and monitoring. Proceedings of the Council on Forest Engineering Proceedings.

23. Laliberte, A.S., Herrick, J.E., Rango, A. and Winters, C. (2010). Acquisition, orthorectification, and object-based classification of unmanned aerial vehicle (UAV) imagery for rangeland monitoring. Photogrammetric Engineering \& Remote Sensing, vol. 76, no. 6, (pp.661-672).

24. Koh, L.P. and Wich, S.A. (2012). Dawn of drone ecology: low-cost autonomous aerial vehicles for conservation. Tropical Conservation Science, vol. 5, no. 2, (pp.121-132).

25. Dufour, S., Bernez, I., Betbeder, J., Corgne, S., Hubert-Moy, L., Nabucet, J., Rapinel, S., Sawtschuk, J. and Trollé, C. (2013). Monitoring restored riparian vegetation: how can recent developments in remote sensing sciences help?. Knowledge and Management of Aquatic Ecosystems, no. 410, (pp.10).

26. Teillet, P.M., Gauthier, R.P., Chichagov, A. and Fedosejevs, G. (2002). Towards integrated earth sensing: The role of in situ sensing. International Archives of Photogrammetry Remote Sensing and Spatial Information Sciences, vol. 34, no. 1, (pp.249-254).

27. Tsihrintzis, V.A., Hamid, R. and Fuentes, H.R. (1996). Use of geographic information systems (GIS) in water resources: a review. Water resources management, vol. 10, no. 4, (pp.251-277). 
28. Metje, N., Chapman, D.N., Cheneler, D., Ward, M. and Thomas, A.M. (2011). Smart pipes-instrumented water pipes, can this be made a reality?. Sensors, vol. 11, no. 8, (pp.7455-7475).

29. Brears, R. (2018). Smart water, smart metering. Retrieved March 25, 2020, from https://medium.com/markand-focus/smart-water-smart-metering-4eff05fca4e9

30. Smith, C. (2019). Why your smart meter may not be so smart after all. Retrieved March 25, 2020, from https://www.bbc.com/news/business-49680943

31. Schlenger, D. (2009). A smart grid for water utilities? Retrieved March 26, 2020, from https://www.smartenergy.com/top-stories/a-smart-grid-for-water-utilities/

32. Bhujun, V. and Bahadoor, D. (2016). Benchmarking water and electricity consumption in hotels in Mauritius. Prodesign. Retrieved October 10, 2019, from https://prodesign.mu/documents/benchmarking-waterelectricity-consumption-hotels-mauritius-2/

33. Government of Mauritius. (2010). Need to adopt energy efficient measures. Retrieved October 10, 2020, from http://www.govmu.org/English/News/Pages/Need-to-adoptenergy-efficient-measures,-says-Deputy-Prime-Minister.aspx

34. Government of Mauritius. (2018). Budget 20182019: Investing in the public utilities sector remains Government's priority. Retrieved March 26, 2020, from http://www.govmu.org/English/News/Pages/Budget20182019-Highlights-Investing-in-the-public-utilities-sectorremains-Government\%E2\%80\%99s-priority-.aspx

35. Central Water Authority. (2020). Central Water Authority, Mauritius. Retrieved March 27, 2020, from http://cwa.govmu.org/Pages/default.aspx

36. Chamber of Agriculture. (2019). Smart agriculture. Retrieved March 26, 2020, from https://chamber-ofagriculture.mu/smart-agriculture/context/chosen-methodology/

37. Proag, V. (2006). Water resources management in Mauritius. European Water, vol. 15, no. 16, (pp.45-57).

38. Ellahee, K. (2014). Hydropower in Mauritius: Holistic Optimisation for Sustainability. Retrieved March 24, 2020,

from https://www.waterpowermagazine.com/features/featurehydrop ower-in-mauritius-holistic-optimisation-for-sustainability4277867/ 